\title{
Decolonizing perspectives of arts education
}

\author{
Rose Martin, ${ }^{1}$ Sunniva Skjøstad Hovde, ${ }^{1}$ Robert Chanunkha ${ }^{2}$ \\ and Pauline Hiroti ${ }^{3}$ \\ ${ }^{1}$ NTNU Norwegian University of Technology and Science, Norway; ${ }^{2}$ MUST Malawi \\ University of Science and Technology, Malawi; ${ }^{3}$ University of Auckland, New Zealand
}

This special issue of JASEd offers insights to current research and practice pertaining to decolonizing perspectives of arts education. As the editors of this special issue, we each come from distinct positionalities, geographical locations, and contextual understandings. We found common ground in the need to discuss and share around the theme of decolonizing arts education. Spurred on by the seismic shifts of power, politics, and polarization that the world is currently experiencing, we noted an urgency to address what this might all mean in and for arts education. Over the past years, and perhaps most recently accelerated by a global pandemic, we have seen uprisings against systemic racism, police brutality, marginalization of minority groups, and calls for real change and reform. Much of the racism, injustice, inequality, and violence we see today stems from colonization and ideologies that maintain systems of domination. Arts education is not immune from such issues and legacies, and it is therefore not immune to the reproduction, support, and nurturing of such systems. This special issue emerges from a desire to extend critical and rigorous discussion surrounding decolonializing perspectives on arts education.

Whilst increasing attention has been given to decolonizing arts education practices and research, many of the approaches, processes and thoughts in arts education are entrenched in colonial histories and structures that perpetuate exclusive, privileging, and Eurocentric agendas. The work of decolonization in arts education is an ongoing process and there is an urgent need for deep dialogue around such issues, to open practices and spaces where we discuss decolonization on a collective level, in professional communities, and on an individual level, where we ask: What work do I have to do as an individual to participate in these ongoing processes of decolonization? To further pursue decolonial arts education practices and research, we see this special 


\section{R. Martin et al.}

issue as an opportunity for educators, artists, and researchers to consider how arts education has been and can be decolonized in various ways, the challenges that sit with the unravelling of a colonial past and the dismantling of ethnocentric thinking, practices, and models. The special issue is comprised of four articles, each their own gemstone offering critical insights and offerings to scholarship surrounding decolonial arts education.

The first article in the special issue, The soil in the lines of my mehndi: Toward a decolonial ritual choreographic methodology by Alesha Mehta and Sarah Foster-Sproull, explores notions of ritual movement practices as a decolonial approach to practice led research. Mehta and Foster-Sproull dive into an investigation of choreographic methodology to foster belonging, cultural identity and empowerment within practice led research in a Western liberal art setting. Leaning on student-centred personal reflections, Mehta and Foster-Sproull propose that ritual movement practice could offer space for cultural representation, belonging and decoloniality in a neoliberal educational context.

Struggling to decolonise ourselves as an antiracist act within the field of the Nordic Community School of Music and Arts by Gry O. Ulrichsen, Helen Eriksen and Zahra Bayati is the second article in the special issue. The article digs into concerns related to the practical implementation of inclusion as recommended in policy documents in art education in general and the Nordic Community School of Music and Arts. Ulrichsen, Eriksen and Bayati ask: What do policy documents mean by inclusion? In what way can or do art educators practice inclusionary strategies? Through working as a trio, the authors explore their embodied knowledge that gives insights to conflicting positions and opportunities to perform intentional antiracist responses in research.

Dance pedagogy claustrophobia: A performative dialogue between auto-ethnographical stop moments from higher education in dance and critical research on dance pedagogy, by Victoria Husby, is the third article of this special issue. She explores how normative dance education, stemming from a Western paradigm characterized by capitalism and individualism, with one 'ideal' dancing body, has socialized her into a hierarchy where there is limited room for criticism of the education taking place. Husby unpacks how she as a student had to 'fit' into the format, in turn creating an encounter of claustrophobia. She uses theory to think with and offers post-qualitative and performative approaches to explore these issues.

The special issue concludes with an article titled Future designs of tertiary dance education: Scanning the field for decolonizing potentials in a major change project at the Department for Dance Pedagogy at Stockholm University of the Arts, by Tone Pernille Østern, Camilla Reppen, Katarina Lion, Katarine Landmark and Elisabet Sjöstedt Eddelholm. This article delivers reflections on a performative hybrid research and development project which offered a scanning of the dance pedagogical field as part of a large change project at the Department for Dance Pedagogy at Stockholm University of the Arts in Sweden. Specifically, decolonial potentials and challenges that were articulated through the scanning process are offered. 
In proposing this special issue, we had hoped for a wide range of voices to emerge, for collaborations to be forged and for boldness to be shared in the articles curated. The articles that we are fortunate enough to share do capture many of our hopes. However, in the process of preparing this special issue, we have also become aware of the gaps, the missing voices, the views that are not included. While it is impossible to always cover all terrain, what has been revealed to us is that this call for articles around the topic of decolonizing arts education piqued the interest in some disciplinary zones more than others. We will not hide that three of the four articles come from a dance context. While this might be due to a variety of factors, we cannot help but ask: Where are the voices from music education? Where are the voices from drama/theatre? With such questions lurking with us on this editorial journey, we cannot resist using this editorial as a platform to also offer provocations around the topic of decolonizing arts education. These provocations include:

- Could the lack of contributions from the music education field come from a strong connection to Eurocentric ideas where the mind and body have been utterly segregated? Within such segregation, has music become defined as an occupation of mind, whilst dance has already been marginalized as bodily?

- Could strong conservatory traditions within the various arts practices be maintaining, sustaining and empowering colonial ideas of music, dance, drama/ theatre, the visual arts, and are these traditions acting as 'gate keepers' of what is perceived to be 'quality' in the arts and in the educational practice of these arts?

- How come do we create other stories about what music, dance, drama/theatre, and visual arts is, if all of the institutions have the same ideas, and dominate through marginalizing particular (and often large) areas of their practices?

- Even though we have taken out some of the content of art music, we might have just replaced it with other genres, but holding on to structures, politics and views on music that are still controlled by specific Eurocentric ideas about music from a time where colonial perspectives where valid?

- Are the decolonizing processes so foreign to some of the arts education fields we sought to engage with that the submission deadlines of this special edition did not give enough time and space to internalize the use of decolonial theory, perhaps because this is the first encounter with such possibilities and challenges?

- We perhaps expected contributions problematizing methods, content, Eurocentrism, the lack of Indigenous premisses or curriculums within music, dance, drama/theatre and visual arts education around the world - why was our reach limited, and why did only particular geographical, disciplinary, and artistic positions respond to our call?

We leave these questions as prompts. We encourage you, as the reader, to allow these queries to sit with you, and we hope that the articles that have been bold to tackle the concerns and issues of decolonizing arts education to propel you to read, think, listen, talk, share, write and perhaps most significantly, act, around this topic into the future. 